\title{
GENETICS AND PLASTID PHYSIOLOGY IN PELARGONIUM. II
}

\author{
R. A. E. TILNEY-BASSETT \\ Botany School, Oxford
}

\section{THE HYPOTHESES}

Received I5.i.65

ON selfing, white-margined Pelargonium zonale cultivars give white offspring, green cultivars give green offspring and reciprocal crosses between the two give various proportions of green, variegated and white offspring showing that plastids are contributed by both pollen and eggs. In many intervarietal crosses, and in the important isogenic reciprocal crosses within the cultivar $P$. $z$. Flower of Spring (TilneyBassett, $1963 b$ ), the results differ from the expected behaviour in two interesting ways:

(1) Instead of giving reciprocal proportions of green and white offspring, the majority of seedlings are green whichever way the cross is made.

(2) Instead of giving the most white offspring when the white plastids enter from the eggs $(W \times G)$, the most white offspring are produced when the white plastids enter from the pollen $(\mathrm{G} \times \mathrm{W})$.

At least three hypotheses can be put forward to explain these results:

(I) Dependent plastid numbers. The simplest explanation is to assume that the proportions of offspring reflect the different plastid contributions from the two parents. This means that the numbers of plastids contributed in any cross are dependent upon whether they are transmitted by a male or female gamete, and whether they are green or white. For this to be true more plastids would have to be transmitted by the male than by the female parent in the $W \times G$ cross of $F$. of Spring. But this would be contrary to the widely held view that the large female egg always contributes more cytoplasmic particles to the zygote than the small male gamete. Moreover, this view has usually been upheld by plastid studies. For the time being the hypothesis must be held in abeyance.

(2) Unequal multiplication rates. It is possible that most seedlings are green because the green plastids multiply faster than the white. In which case, one would definitely expect to obtain the most green seedlings when the female parent was green instead of when the male parent was green. To overcome this difficulty, one must add the unlikely rider that the multiplication rates of green and white plastids are not only unequal but are also different in reciprocal crosses. This seems to be particularly unsatisfactory in view of the fact that in Enothera, for example, white plastids multiply at the same rates as the green plastids from which they have been derived. Again the hypothesis must be held in reserve until further evidence is available. 
(3) Embryo selection. As a working hypothesis, I have attempted to explain these results by suggesting ( $1963 b$ ) that the developing white embryos are particularly lethal in $W \times G$ crosses but not in $\mathrm{G} \times \mathrm{W}$ crosses. This was suggested particularly by the much greater lethality of white compared with green embryos on selfing, and by the presence of numerous white seedlings from the $G \times W$ cross compared with their virtual absence from the $W \times G$ cross. The hypothesis was further supported by the observation that as many as half the embryos do indeed die off before reaching maturity. But since this lethality is common to both crosses, it becomes necessary to further postulate that there is a strong preferential selection against the survival of white embryos in the $W \times G$ cross but not in the $G \times W$ cross. How could such a one-sided selection arise? I believe it could operate through the action of the endosperm. It seems likely that the endosperm, with its double nuclear contribution from the female, will contain predominantly green plastids in the $G \times W$ cross and predominantly white plastids in the reciprocal cross. I suggest that most white embryos survive only if they have a predominantly green endosperm to nourish them. Hence many more embryos die in the $\mathrm{W} \times \mathrm{G}$ cross than in the $\mathrm{G} \times \mathrm{W}$ cross. We know, however, that half the embryos die in both crosses, possibly because of competition between themselves. I therefore presume that in the $W \times G$ cross, the pressure of competition selects first against the undernourished white embryos, while in the $\mathrm{G} \times \mathrm{W}$ cross the competition selects equally against green, variegated and white embryos. Moreover, the similar fertility of the two crosses suggests that the one-sided selection in the $W \times G$ cross not only lowers the proportion of white embryos but, because of the reduced competition this produces, actually allows many green embryos that would otherwise have died to survive.

It is the purpose of this article to describe experiments designed to test the selection hypothesis. At the same time I propose to compare the behaviour of P.z. Flower of Spring with a second cultivar, P.z. Dolly Varden.

\section{MATERIALS AND METHODS}

(I) Isogenic cultivars

The cultivars F. of Spring and D. Varden are both white-over-green periclinal chimeras (GWG). The leaves of F. of Spring have a wide white margin whereas the leaves of $D$. Varden have no more than a narrow white fringe. I have illustrated both plants in my first report ( $1963 b$, plate I, figs. 7 and 8). In white shoots (WWW) derived from $D$. Varden, one can see scattered in the white mesophyll tissue occasional tiny green islands of unknown origin; these islands are not found in the white tissue of $\mathrm{F}$. of Spring.

From both chimeras I have been able to isolate, and subsequently propagate, the pure green bud variants. Since these bud variants arise without any change in the nucleus, the green and chimera clones within each cultivar are isogenic; they differ from each other only in relation to the germ layer (L II) which possesses green or white plastids respectively. We may therefore assume that differences 
in the progenies and fertilities of selfs and crosses are dependent upon differences in behaviour of the two types of plastid. The effects of the plastids on development can therefore be separated from the effects of the nucleus.

\section{(ii) Cultivation, controlled pollination and germination}

The methods which I have already described $(1963 b)$ for cultivation, controlled pollination and germination have continued to prove satisfactory.

\section{(iii) Macroscopic estimation of fertilisation}

The macroscopic estimation of fertilisation is based on the assumption that all ovules continuing to expand after pollination have been fertilised whereas the non-expanding ovules have not. The large expanding and the small non-expanding ovules are separated from each other by dissecting them out of the carpels under a binocular microscope. This is done as soon as the size difference between the ovules becomes obvious which is at least three days after pollination, or they can be dissected at any time thereafter. The estimated percentage fertilisation is calculated from the observed number of expanded ovules compared with the total number of ovules, expanded and non-expanded together.

\section{(iv) Microscopic estimation of fertilisation}

In order to check the macroscopic estimation of fertilisation, approximately 200 ovules from each self and cross were microscopically examined for the presence of a developing embryo and endosperm. Whole ovaries were removed 5 days after pollination, embedded in paraffin wax, serially sectioned with a hand microtome, stained in safranin and fast green and finally mounted on glass slides according to standard procedures. Each ovule was scored according to one of the following categories:

(I) Full ovules containing a developing embryo and endosperm. These have been fertilised.

(2) Empty ovules which contain no embryo or endosperm. I have not been able to establish whether these are definitely structurally and functionally normal but they do appear to contain an embryo sac capable of being fertilised.

(3) Shrivelled ovules which are structurally abnormal. They contain no embryo sac, they are distorted in shape, modified in cell structure and usually very reduced in size. These could not possibly be fertilised.

The estimated percentage fertilisation is calculated from the number of full ovules compared with the total number of ovules.

\section{(v) Estimation of number: of plastids transmitted in crosses}

Embryos and seedlings are always scored as numbers of green, variegated or white individuals. It is, however, useful to be able to express these observations in terms of numbers of plastids contributed to the offspring by each of the parents. Exact numbers cannot be given without actually counting the plastids in the germ cells and the fertilised eggs, and this cannot be done. The nearest approach is to estimate the relative proportions of plastids from the two parents. This can be done approximately by assuming that each fertilised egg receives at least two plastids. A pure green embryo can therefore be said to represent two green plastids while a pure white embryo represents two white plastids. A variegated embryo, on the other hand, clearly has an effective plastid contribution from both parents and can therefore be said to represent one green plus one white plastid. Hence, the total relative number of green plastids from a particular cross equals twice the observed number of green embryos or seedlings plus the actual number of variegated embryos or seedlings. Similarly, the total relative number of white plastids equals 
twice the observed number of white embryos or seedlings plus the actual number of variegated embryos or seedlings. Since we know which parent contributed the green and which the white plastids, the ratio of these two totals equals the ratio of the number of plastids contributed by one parent compared with the number contributed by the other parent. These two ratios will not in fact be equal, if during embryo development the green and white plastids do not sort-out at random, or if one type of plastid multiplies more rapidly than the other, or if selection results in the death of one type of embryo more than any other.

\section{BREEDING AND FERTILITY}

\section{(i) Selfing and isogenic reciprocal crosses}

The results of selfing and isogenic reciprocal crosses in the two Pelargonium cultivars are shown in table $\mathrm{I}$. The general picture is one of similarity, but on closer inspection a number of important differences can be seen.

(a) Similarities between Flower of Spring and Dolly Varden. On selfing, green germ layers give green offspring, and white germ layers give mostly white offspring; the occasional green seedlings instead of white can be attributed to layer alterations which cause the ovules to develop in a green layer instead of the white layer. The layer alteration is probably GWG $\rightarrow$ GGW (Tilney-Bassett, 1963a). Reciprocal crosses give green, variegated and white offspring in various proportions.

The selfed green and the reciprocal crosses have a poor total fertility of under 28 per cent.; a fairly good germination shows that the fertility losses occur largely before germination. The selfed white suffers severe fertility losses at all stages since the poor germination also contributes significantly to the very low total fertility of under 2 per cent.

(b) Differences between Flower of Spring and Dolly Varden. The total fertilities of the selfed green and the two reciprocal crosses in F. of Spring are all within 3 per cent. of each other. By contrast, D. Varden shows a striking gradation in its total fertility values $-\mathrm{G} \times \mathrm{G}, 27.4 \mathrm{per}$ cent.; $\mathrm{G} \times \mathrm{W}, 20.2$ per cent.; and $\mathrm{W} \times \mathrm{G}, 13.6$ per cent. Since the nucleus is constant, this gradation in fertility is presumably connected with the different plastid combinations in a way that is not apparent in F. of Spring.

The two cultivars also show differences between each self and cross as follows:

$\mathrm{G} \times \mathrm{G}$ : The fertility of F. of Spring is lower than that of D. Varden.

$\mathrm{G} \times \mathrm{W}$ : The fertility of F. of Spring is lower than that of D. Varden. Besides green and variegated seedlings, the F. of Spring cross produced numerous white seedlings whereas the $\mathrm{D}$. Varden cross produced only a few.

$\mathrm{W} \times \mathrm{G}$ : The fertility of $F$. of Spring is higher than that of $D$. Varden. The seed germination of this D. Varden cross was poorer than the germination of other crosses.

$\mathrm{W} \times \mathbf{W}:$ After well over one thousand pollinations, the significantly 
lower fertility of D. Varden makes it clear that its white embryos are less viable than those of F. of Spring.

The proportion of variegated offspring is lower in F. of Spring than in D. Varden. Their values are interesting to compare. F. of Spring gave dissimilar proportions of variegated offspring -7.4 per cent. in the $\mathrm{G} \times \mathrm{W}$ cross compared with 18.8 per cent. in the reciprocal.

TABLE I

Results of selfing and isogenic reciprocal crosses within two

Pelargonium cultivars

\begin{tabular}{|c|c|c|c|c|c|c|c|c|c|}
\hline \multirow{3}{*}{$\begin{array}{l}\text { Self or } \\
\text { cross }\end{array}$} & \multicolumn{6}{|c|}{ Total nos. and percentages } & \multirow{2}{*}{\multicolumn{3}{|c|}{ Offspring }} \\
\hline & \multirow{2}{*}{$\begin{array}{l}\text { Ovules } \\
\text { pollnd. }\end{array}$} & \multicolumn{4}{|c|}{ Seeds } & \multirow{2}{*}{$\begin{array}{c}\text { Total } \\
\text { fertility } \\
\text { per cent. }\end{array}$} & & & \\
\hline & & Full & $\begin{array}{l}\text { Per cent. } \\
\text { full }\end{array}$ & Germd. & $\begin{array}{l}\text { Per cent. } \\
\text { germd. }\end{array}$ & & G & V & W \\
\hline \multicolumn{10}{|c|}{ 1. Flower of Spring } \\
\hline $\begin{array}{l}G \times G \\
G \times W \\
W \times G \\
W \times W\end{array}$ & $\begin{array}{r}1510 \\
1140 \\
800 \\
1170\end{array}$ & $\begin{array}{l}331 \\
226 \\
152 \\
154\end{array}$ & $\begin{array}{l}21 \cdot 9 \\
19 \cdot 8 \\
19 \cdot 0 \\
13 \cdot 2\end{array}$ & $\begin{array}{r}295 \\
191 \\
144 \\
17\end{array}$ & $\begin{array}{l}89 \cdot 1 \\
84 \cdot 5 \\
94 \cdot 7 \\
11 \cdot 0\end{array}$ & $\begin{array}{r}19.5 \\
16.8 \\
18.0 \\
1.5\end{array}$ & $\begin{array}{r}294 \\
104 \\
115 \\
3 \dagger\end{array}$ & $\begin{array}{l}1 * \\
14 \\
27 \\
\cdots\end{array}$ & $\begin{array}{r}73 \\
2 \\
14\end{array}$ \\
\hline \multicolumn{10}{|c|}{ 2. Dolly Varden } \\
\hline $\begin{array}{l}\mathbf{G} \times \mathbf{G} \\
\mathbf{G} \times \mathbf{W} \\
\mathbf{W} \times \mathbf{G} \\
\mathbf{W} \times \mathbf{W}\end{array}$ & $\begin{array}{r}270 \\
540 \\
360 \\
1590\end{array}$ & $\begin{array}{r}88 \\
137 \\
81 \\
102\end{array}$ & $\begin{array}{r}32 \cdot 6 \\
25 \cdot 4 \\
22 \cdot 5 \\
6 \cdot 4\end{array}$ & $\begin{array}{r}74 \\
109 \\
49 \\
4\end{array}$ & $\begin{array}{r}84 \cdot I \\
79 \cdot 6 \\
60 \cdot 5 \\
3 \cdot 9\end{array}$ & $\begin{array}{r}27 \cdot 4 \\
20 \cdot 2 \\
13.6 \\
0.3\end{array}$ & $\begin{array}{l}74 \\
78 \\
36 \\
1 \dagger\end{array}$ & $\begin{array}{l}\ldots \\
27 \\
13 \\
\ldots\end{array}$ & $\begin{array}{r}\ldots \\
4 \\
\ldots \\
3\end{array}$ \\
\hline
\end{tabular}

* Variegated seedlings is a new mutant.

† Green seedlings are probably derived from green LI following layer alterations. The three green seedlings produced by $F$. of Spring all came from the same flower.

D. Varden, on the other hand, gave similar proportions of variegated offspring -24.8 per cent. in the $\mathrm{G} \times \mathrm{W}$ cross and 26.5 per cent. in the reciprocal.

\section{(ii) Fertility losses}

Nearly every Pelargonium flower has five carpels containing a total of ten ovules, and yet after self and cross pollinations in F. of Spring and D. Varden an average of less than three (30 per cent.) survive to the seedling stage (table 1 ). It seemed possible that at least a part of these heavy fertility losses might be affected by the specific plastid content. I have therefore analysed the causes of the fertility drop which can be divided into two main stages, namely the losses before and after fertilisation.

(a) Pre-fertilisation losses. Macroscopic observations, after self or cross pollinations in F. of Spring, show that less than $4^{\mathrm{I}}$ per cent. of the ovules grow, which suggests that less than $4 \mathrm{I}$ per cent. are fertilised (table 2). A much smaller sample from D. Varden suggests 
that no more than 43 per cent. of the ovules are fertilised. Microscopical examination of serial sections confirms these estimates although indicating that they may sometimes be rather high. At the same time, the serial sections show not only why numerous ovules are unfertilised, but they also reveal important causes for variable estimates of fertilisation.

Shrivelled ovules. Numerous ovules are unfertilised because in the average flower about six ovules are shrivelled and incapable of being fertilised. The actual number of shrivelled ovules per flower varies between a minimum of two and a maximum of all ten; five or six shrivelled ovules occur equally often and seven slightly less often, but other numbers are much rarer.

Since the number of shrivelled ovules is a character of the mother, isogenic selfs and crosses having the same mother should have the same average proportion of shrivelled ovules. Hence it is entirely due to the variability between samples that a io per cent. difference was found in the number of shrivelled ovules between the F. of Spring $\mathrm{G} \times \mathrm{G}$ self and $\mathrm{G} \times \mathrm{W}$ cross and similarly between the $\mathrm{D}$. Varden $G \times G$ self and $G \times W$ cross. In $F$. of Spring the $G \times G$ sample had a bias below average of about five shrivelled ovules per flower and so a high fertility of $40^{\circ}$ I per cent. was achieved. But in D. Varden the $\mathrm{G} \times \mathrm{W}$ sample had a bias above average of about seven shrivelled ovules per flower, which was largely responsible for the low fertilisation of 24.7 per cent. compared with 38.5 per cent. for the selfed green with a normal average of about six shrivelled ovules per flower. The possibility of such wide variations between samples must clearly be borne in mind when considering the significance of gradations in fertility such as have been found in D. Varden (table I).

Empty ovules. Flowers occasionally contain empty ovules which appear to be of normal structure but they have not been fertilised. They are much larger than the shrivelled ovules and they remain turgid for several days after pollination. Consequently they may sometimes be erroneously scored as fertilised ovules and thereby cause the macroscopic estimates of fertility to be slightly higher than they should.

Green and white germ layers. The estimated fertilisation of F. of Spring when the ovules were developed in a white germ layer (GWG), was slightly lower than when the ovules were developed in a green germ layer (GGG), and the proportion of shrivelled ovules found in serial sections was higher in the chimera (table 2). This difference may be significant because under poor light conditions in late autumn the fertility of the chimera is adversely affected more than the green clone. The pollinations were made under normal daylight conditions in the greenhouse between April and September. It is quite possible that occasionally the light was sufficiently poor to affect the ovule development in the chimera but not in the green plants. There is no suggestion of differences in fertility between the germ layers of 


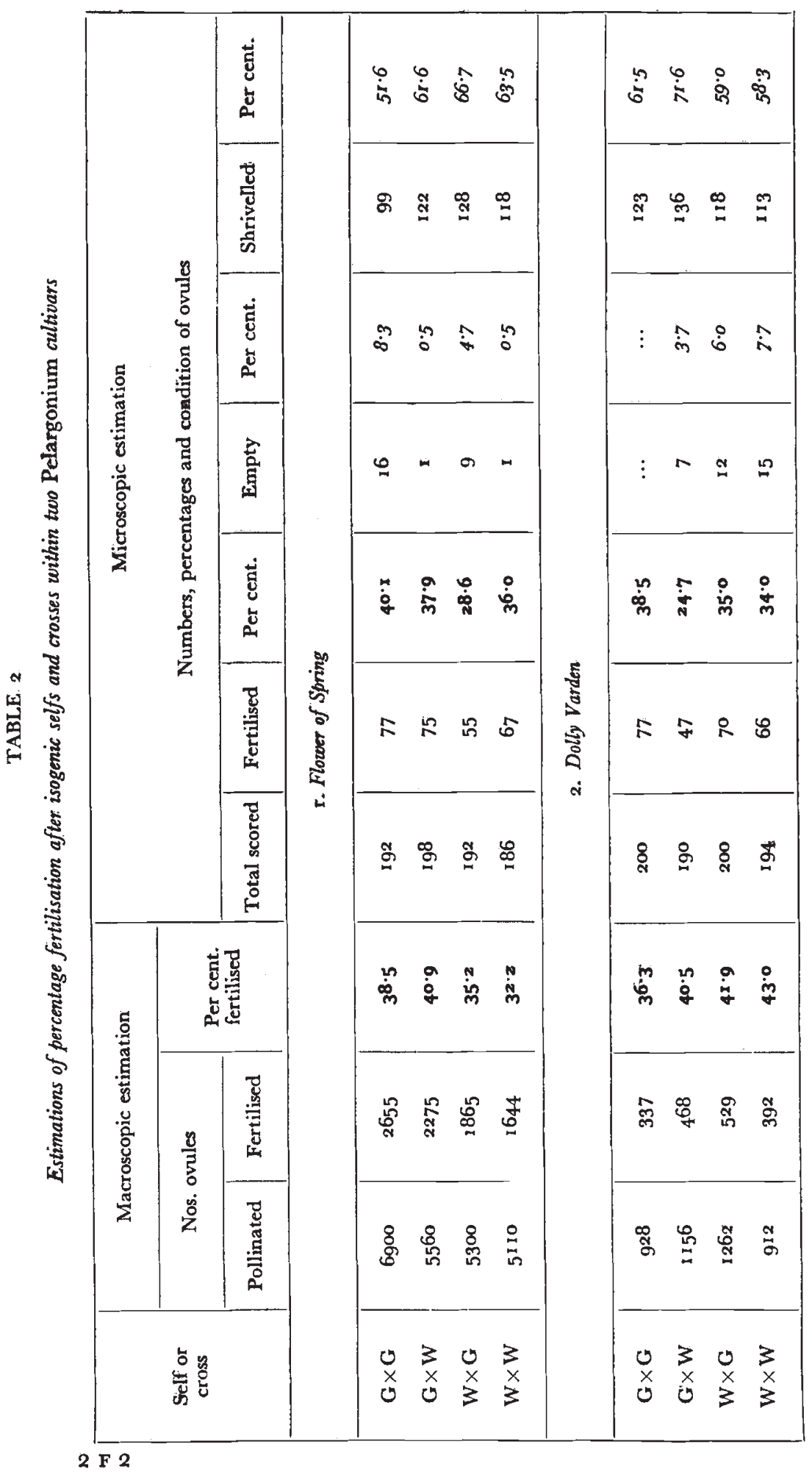


D. Varden. Perhaps the much smaller quantity of white tissue in the white-fringed D. Varden leaf, compared with the wide white margin in the F. of Spring leaf, enables the germ cells to be nourished better. Moreover, green and chimera clones of D. Varden flower in winter when both F. of Spring clones stop flowering, which suggests that D. Varden is more tolerant of poor light.

Pollen germination. In my first paper $\left(1963^{b}\right)$ I attributed the heavy fertility losses, which I now find to be caused by the shrivelled ovules, to pollen tube failure. Pollen tube failure is presumably still responsible for the non-fertilisation of the empty ovules. A comparison between the estimated fertilisation with a green pollen parent $(G \times G$ plus $W \times G)$ and the estimated fertilisation with a white pollen parent $(W \times W$ plus $G \times W)$, shows no significant difference between them. Evidently pollen tubes germinate equally successfully whether they contain green or white plastids.

(b) Post-fertilisation losses. Although the variability prevents me from giving an exact figure, it is clear that in all selfs and crosses of both cultivars not more than 40 per cent. of the ovules are fertilised; it is the fate of this portion that I now wish to consider. The postfertilisation losses consist of the following two parts:

(I) Losses independent of the plastid content and common to all selfs and crosses.

(2) Additional losses caused by the introduction of white plastids.

Since no white plastids enter into the $G \times G$ selfs, their fertility losses provide the necessary control against which we can compare the fertility losses when white plastids are introduced. In the selfed green clones, the total fertility is 19.5 per cent. in F. of Spring and 27.4 per cent. in D. Varden (table I) indicating a post-fertility loss of about 20 and 13 per cent. respectively. What causes these losses?

Genetical causes. Serial sections show that several lethal factors halt embryo development. Out of 52 selfed green, five day old F. of Spring ovules I found one with a poorly developed nuclear endosperm and apparently no embryo, two with an embryo but apparently no endosperm, and four in which embryo expansion was severely restricted by the ovule walls pinching together. Between ten and fifteen days the expansion of normal embryos increases their length from under I to over $2 \mathrm{~cm}$., but a number are incapable of this expansion. Still other lethal effects may operate later in development but I have not yet looked for them. Since the nucleus is always selfed in isogenic selfs and crosses, it is possible that these abnormalities are caused by the segregation of lethal recessive genes and account for much or perhaps all of the fertility drop common to selfs and crosses.

Environmental causes. A number of embryos may die through such environmental effects as lack of food supply owing to competition between ovules of the same flower. However, since there appears to be no competition between whole flowers of an inflorescence no matter how many flowers it contains (Tilney-Bassett, $1963 b$ ), there is 
no particular reason to suspect competition between developing ovules within a flower.

In my first paper $\left(\mathrm{I}_{9} 6_{3} b\right)$ I drew attention to the interesting fact that about 20 per cent. of the developing ovules in F. of Spring are in the lower and 80 per cent. in the upper position in each carpel. It occurred to me that any competition between ovules might favour the survival of the upper rather than the lower or vice versa. I therefore determined at five-day intervals, from five to thirty days after pollination, the proportion of ovules that had been fertilised and which still appeared good, and the proportion that had been fertilised but which were evidently dying because they had lost their turgidity and were gradually becoming brown and wrinkled. I was able to recognise a steadily increasing proportion of dying ovules at each five-day interval, but in all selfs and crosses I could find no significant difference between the survival of upper and lower ovules. There is evidently no competition between them. I have not made similar determinations for D. Varden.

White plastids. In addition to the common fertility drop, further losses are caused by the introduction of white plastids. This is shown especially by the extremely low fertilities of the $W \times W$ selfs. The F. of Spring crosses have a fertility which is only slightly lower than the selfed green. Evidently the lethal effects of the white plastids are greatly reduced by the presence of green plastids either in the embryo, or in the endosperm, or in both tissues. The gradations in fertility shown by D. Varden, on the other hand, suggest that its white plastids lower the fertility even when green plastids are present, especially when the white plastids enter from the egg. A comparison of the crosses therefore strengthens the conclusion, based upon a comparison of the $\mathrm{W} \times \mathrm{W}$ selfs, that the lethality of the white plastids is greater in D. Varden than in F. of Spring.

\section{(iii) Selection against white embryos}

The young Pelargonium seed has a transparent wall enabling normal plastids in the embryo to develop into green chloroplasts so that within ten days of pollination it is possible to see whether sortingout of plastids is giving rise to green, white or variegated cotyledons. Between twenty-five and thirty days after pollination when the seeds ripen, the transparent wall becomes an opaque dark brown and the chloroplasts lose their chlorophyll. The chlorophyll is quickly restored again to the cotyledons when the seeds germinate. The plastids in the endosperm do not develop into chloroplasts. Since almost all embryos reach the stage of early cotyledon development, almost all fertilised ovules can be scored before lethal effects set in. I have therefore been able to compare counts of green, variegated and white embryos at ten days with counts of the seedlings (table 3 ). From these counts, I have first estimated the proportions of green and white plastids, and secondly determined the changes in these proportions 
between ten days and germination. The proportions of green, variegated and white embryos turn out to be of the same order as the proportion of seedlings, the green embryos predominating. The observed decreases of 10-17 per cent. in the proportion of white represent the elimination of only a few white embryos. Therefore, the predominance of green offspring in the $W \times G$ crosses of both cultivars is not the result of a vigorous selection against white embryos during the fertility drop. Furthermore, the gradations in total fertility in D. Varden cannot be explained by the selective elimination of different numbers of white embryos. Thus, far too few white embryos are produced for selection against them to be enough to uphold the selection hypothesis; where they do occur in large numbers in the $\mathrm{F}$. of Spring $\mathrm{G} \times \mathrm{W}$ cross there is no selection against them.

Besides decreases in the proportion of white embryos between ten days and germination the D. Varden crosses show decreases in the proportion of variegated embryos-the $\mathrm{G} \times \mathrm{W}$ cross decreased from $3^{1} \cdot 6$ per cent. variegated embryos to 24.8 per cent. variegated seedlings, and the $\mathrm{W} \times \mathrm{G}$ cross decreased from $4 \mathrm{I}^{\mathrm{I}} \cdot 3$ per cent. variegated embryos to 26.5 per cent. variegated seedlings (table 3 ). But for the loss of some white embryos as well, these drops in the proportion of variegation would be even greater. I estimate that the combined fertility drop caused by selective loss of white and variegated embryos in the two crosses accounts for a drop of approximately 3 per cent. in their total fertility values (table I), but the difference between them is only about 0.2 per cent. Clearly non-reciprocal selection against white and variegated embryos is insignificant and does not therefore account for the difference in fertility between reciprocal crosses. Two alternative explanations seem possible. Firstly, the gradation in fertility values may be due to unfortunate samples; this point can be decided only by repeating the breeding experiments. Secondly, there may be a strong selection against endosperms containing predominantly white plastids irrespective of the embryo colour. It seems likely that the endosperm, especially with its double nuclear contribution from the female, will receive predominantly white plastids more often in the $W \times G$ cross, in which the lowest fertility is found, than in the $G \times W$ cross.

\section{PLASTID TRANSMISSION}

The selection hypothesis clearly does not account for the predominance of green offspring in the two isogenic reciprocal crosses, and the possibility of different multiplication rates remains unsatisfactory. We are therefore left with the alternative that the proportions of green : variegated : white embryos or seedlings reflect the respective plastid contributions of the two parents. In the two cultivars investigated this requires a slight adjustment for the seedling values owing to selection against a few white and variegated embryos during seed development. It is quite likely that a similar selection sometimes 


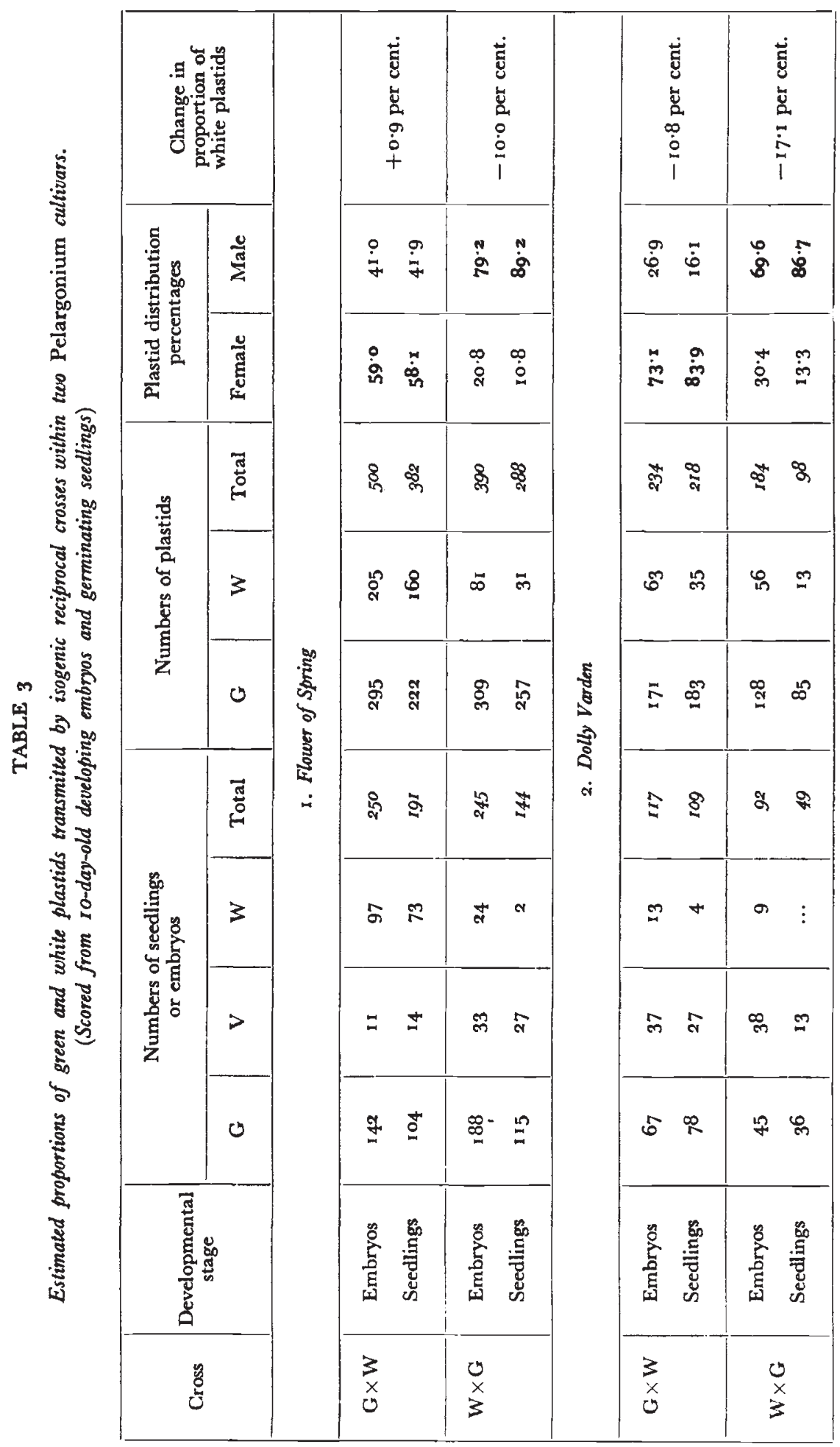


occurs in non-reciprocal crosses but there is no reason to suspect that it would be any more significant. Green and white plastids may multiply at different rates in non-isogenic crosses but again there is no reason to suspect this. I therefore feel that a comparison of nonisogenic with isogenic crosses is valuable, even though provisional. Accordingly, I have presented in table 4 the seedling results of the isogenic crosses together with most of the intervarietal crosses from my first paper ( $1963 b$, table 5 ). From these results, I have calculated the plastid distributions and the proportions of variegated seedlings for each cross.

\section{(i) Plastid distribution}

In all crosses, more green plastids are transmitted to the offspring than white. Hence the plastid transmission is predominantly maternal in the $\mathrm{G} \times \mathrm{W}$ crosses and predominantly paternal in the $\mathrm{W} \times \mathrm{G}$ crosses. The proportion of green plastids, however, is not the same in reciprocal crosses. In five sets of crosses, the proportion of green plastids is unexpectedly lower when they are transmitted by the female egg $(G \times W)$ than when they are transmitted by the male gamete $(W \times G)$. Evidently green plastids, and consequently white plastids, are most successful when they are transmitted by the pollen. By contrast, this behaviour is reversed in the two sets of intervarietal crosses with Grystal Palace Gem as the source of the green plastids. This time it agrees with the expectation since green and white plastids are transmitted most successfully by their female parent. Each pair of crosses differs from the others in the extent to which its green or white plastids are transmitted more successfully by the male than by the female or vice versa. Hence the crosses can be arranged in a series showing steps in the gradation from maternal advantage to paternal advantage. In table 4 , I have expressed this gradation in percentage values which are calculated by subtracting the lowest green or white plastid distribution from the highest green or white plastid distribution respectively; the difference between the two green values is equal to the difference between the two white values. Providing green plastids are always more successful than white, the white plastid distribution can never go above 50 per cent., hence the theoretical range of the scale is from a maximum of 50 per cent. female advantage to a maximum of 50 per cent. male advantage.

If we now compare the seven pairs of crosses we see that they fit into four groups corresponding to the four sources of green plastids. The group with Crystal Palace Gem as the source of the green plastids shows a maternal advantage while the other three groups show a paternal advantage. The $2 \cdot 8$ per cent. paternal advantage of D. Varden, however, is very slight indicating that white plastids are nearly as successful in the $W \times G$ cross as in the $G \times W$ cross, similarly green plastids are nearly as successful in the $G \times W$ cross as in the $\mathrm{W} \times \mathrm{G}$ cross. It is interesting to note that the paternal advantage of 


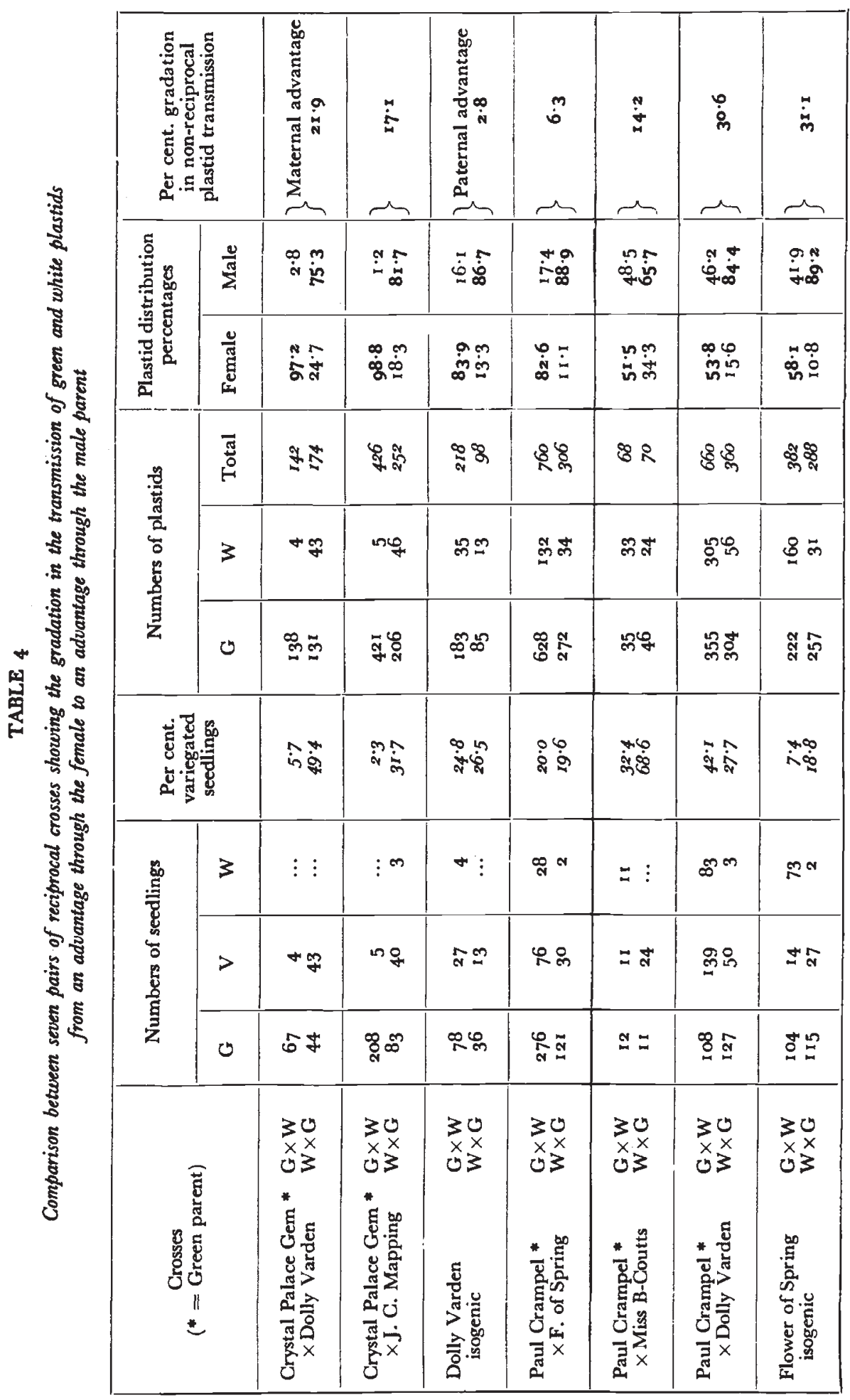


D. Varden based on scoring embryos is very similar, namely 3.5 per cent. At the moment, the three Paul Crampel crosses are grouped together, but the variation between them is quite wide so their grouping would probably have been interrupted had more crosses been made. Indeed, the paternal advantage of F. of Spring based on scoring embryos is 20.2 per cent. and therefore falls within the P. Crampel grouping. In the intervarietal $\mathrm{W} \times \mathrm{G}$ cross between $P$. Crampel and Kathleen Harrop (Tilney-Bassett, 1964) all the seedlings were green; in the reciprocal cross, because of sterility, only three seedlings were obtained, again green. It is possible that with more pollinations a few variegated or white seedlings might have been produced by the $\mathrm{G} \times \mathrm{W}$ cross. In which case the transmission of green and white plastids would have an advantage from the male similar to the three P. Crampel crosses shown in table 4 .

Since green plastids always predominate, their behaviour is more important than that of white plastids in determining whether transmission is most successful through the male or the female. Thus in the cross $P$. Crampel $\times D$. Varden, the white $D$. Varden plastids are most successfully transmitted by the pollen, whereas in the cross C. P. Gem $\times$ D. Varden, the same white D. Varden plastids are now most successful when transmitted by the egg. Nevertheless, in the three P. Crampel crosses in which the green plastid contribution is constant, the three different white plastids are able to cause significant variations in the advantage of pollen transmission.

\section{(ii) Sorting-out}

The proportion of variegated seedlings produced by any cross is directly related to the rate of sorting-out and is therefore dependent upon any factors controlling it. Assuming sorting-out is at random and green and white plastids multiply at the same rate, then the higher the total number of plastids or the more equal the proportions of the two types, the slower the sorting-out. I find that variations in these two principles cause considerable differences among the crosses which are worthy of further comment. Accordingly, I propose to list them in the following five groups in which I include the data for the percentage of variegated seedlings and the percentage distribution of white plastids.

(I) $W \times G$ crosses I

F. of Spring lsogenic cross 10.8 per cent. white plastids

P. Crampel $\times$ F. of Spring II. I per cent. white plastids

D. Varden isogenic cross I3.3 per cent. white plastids

P. Crampel $\times$ D. Varden I $5^{\circ} 6$ per cent. white plastids

C. P. Gem $\times$ J. C. Mapping I8.3 per cent. white plastids

I 8.8 per cent. variegated seedlings

19.6 per cent. variegated seedlings

$26 \cdot 5$ per cent. variegated seedlings

$27 \cdot 7$ per cent. variegated seedlings

$3^{I} \cdot 7$ per cent. variegated seedlings 
In this group, increasing proportions of variegated seedlings are associated with increasing proportions of white plastids. In the two P. Crampel crosses, the number of green plastids should be the same in both, hence D. Varden, with the higher plastid contribition and slower sorting-out, must contribute more white plastids than F. of Spring. In the remaining three crosses each green parent as well as each white parent is different, hence the variable proportions of variegated offspring may be due to the dissimilar plastid distributions, which we have measured, or to slightly different plastid totals, which we can only guess at, or to both factors.

(2) $\mathrm{W} \times \mathrm{G}$ crosses II

C. P. Gem $\times$ D. Varden 24.7 per cent. white plastids $49^{\circ} 4$ per cent. variegated seedlings

P. Crampel $\times$ Miss B-Coutts 34.3 per cent. white plastids 68.6 per cent. variegated seedlings

In these two crosses a very high proportion of variegated offspring is accompanied by the unexpected absence of white seedlings. This is quite exceptional because many other crosses with smaller contributions of white plastids have nevertheless sorted-out to give white seedlings. I believe the white embryos must be lethal in these crosses.

(3) $\mathrm{G} \times W$ crosses I

C. P. Gem $\times$ J. C. Mapping

I.2 per cent. white plastids $\quad 2 \cdot 3$ per cent. variegated seedlings

C. P. Gem $\times$ D. Varden

2.8 per cent. white plastids 5.7 per cent. variegated seedlings

A very low proportion of variegated seedlings is associated with a very small contribution of white plastids and the absence of white seedlings. The rapid sorting-out to produce predominantly pure green cells suggests that the number of green plastids in the mixed zygote must have been very much greater than the number of white plastids.

(4) $\mathrm{G} \times W$ crosses II

P. Crampel $\times$ F. of Spring

I 7.4 per cent. white plastids 20.0 per cent. variegated seedlings

D. Varden isogenic cross

I6. I per cent. white plastids $24 \cdot 8$ per cent. variegated seedlings

These two crosses have proportions of variegated seedlings and plastid distributions similar to the first $W \times G$ group indicating that their total plastid content falls within a similar range.

(5) $\mathrm{G} \times W$ crosses III

F. of Spring isogenic cross $4 \mathrm{I} \cdot 9$ per cent. white plastids $\quad 7 \cdot 4$ per cent. varigated seedlings

P. Crampel $\times$ Miss B-Coutts 48.5 per cent. white plastids 32.4 per cent. variegated seedlings

P. Crampel $\times$ D. Varden $46 \cdot 2$ per cent. white plastids $42 \cdot 1$ per cent. variegated seedlings

Since the isogenic cross produces numerous white as well as green seedlings, the very low proportion of variegated offspring indicates 
that the total number of plastids in the mixed zygotes must have been small. The two $\mathrm{P}$. Crampel crosses have received a similar proportional contribution of white plastids, but their much greater numbers of variegated seedlings indicate a higher total plastid content.

Analysis of these isogenic and intervarietal crosses has already taken us a long way towards understanding the Pelargonium problem. Further crosses, especially of new combinations between the present cultivars, will clearly produce still more interesting results in the future.

\section{SUMMARY}

I. Comparison between the sorting-out of seedlings and embryos after isogenic reciprocal crosses (table 3 ), coupled with fertility studies (table 2), leads me to conclude that the numbers of plastids contributed in any cross are dependent upon whether they are transmitted by a male or a female gamete, and whether they are green or white.

2. In all intervarietal and isogenic crosses there are more green offspring than white, consequently the inheritance is predominantly maternal in $\mathrm{G} \times \mathrm{W}$ crosses and predominantly paternal in $\mathrm{W} \times \mathrm{G}$ crosses (table 4).

3. Green and white plastids are more successfully transmitted through their female reproductive cells in some crosses and through their male gametes in others (table 4).

4. A low fertilisation is caused by numerous bad ovules and the failure of the pollen to fertilise a few good ones (table 2). Failure of many embryos to mature is due to the lethal effects of inbreeding in isogenic crosses and to white plastids.

5. The lethality of white plastids is greatly reduced by the presence of green plastids; D. Varden white plastids are more lethal than those of $F$. of Spring (table $I$ ).

6. A slight selection occurs in some crosses against white and variegated embryos (table 3 ); it is too small to explain the differences between reciprocal crosses.

7. Gradations in the fertility of D. Varden selfs and crosses may be due to selection against endosperms containing predominantly white plastids irrespective of the embryo content.

Acknowledgments. - I wish to thank Professor C. D. Darlington, F.R.S., for his continued encouragement throughout the course of this work. My thanks are also due to Miss Christine Cox for her valuable assistance. This work has been made possible by a D.S.I.R. research grant.

\section{REFERENCES}

TILNEY-BASSETT, R. A. E. 1963a. The structure of periclinal chimeras. Heredity, $18,265-285$.

TILNEY-BASSETt, R. A. E. $1963 b$. Genetics and plastid physiology in Pelargonium. Heredity, $18,485-504$.

TILNEY-BAsSETT, R. A. E. 1964. Failure to transmit mutant plastids in a Pelargonium cross. Heredity, 19, 516-518. 